\title{
Lung Ultrasound as a Monitoring Tool
}

\author{
Jinwoo Lee, M.D. ${ }^{1,2}$ (1)
}

${ }^{1}$ Division of Pulmonary and Critical Care Medicine, Department of Internal Medicine, Seoul National University Hospital, Seoul, ${ }^{2}$ Department of Internal Medicine, Seoul National University College of Medicine, Seoul, Republic of Korea

Lung ultrasound has proven to be useful in detecting pneumothorax, interstitial syndrome, and lung consolidation. It is easily applied at the bedside, in real-time, and free of radiation hazards. Recently, the use of lung ultrasound has moved from a diagnostic tool to a monitoring tool for lung aeration quantification. This article reviewed the use of lung ultrasound in monitoring acute pulmonary edema, acute respiratory distress syndrome, and pneumonia, and how it could be used to monitor changes during the application of mechanical ventilation or other treatments for respiratory failure.

Keywords: Ultrasonography; Monitoring; Lung; Extravascular Lung Water

\section{Introduction}

Over the last two decades, lung ultrasound (LUS) has emerged as a useful, radiation-free imaging technique that can be quickly done at the bedside to assess patients in the intensive care unit (ICU) or emergency department. An international evidence-based recommendations for point-of-care LUS suggested the use of LUS to diagnose pneumothorax, interstitial syndrome and lung consolidations ${ }^{1}$ and its use has been expanded to neonatal and pediatric critical care setting ${ }^{2}$. Increasing evidence supports superior diagnostic performance of LUS compared to bedside chest X-ray in critically ill patients ${ }^{3,4}$. Recently, the use of LUS has moved from being a diagnostic tool to a monitoring tool for lung aeration quantification. LUS may be used to monitor various pulmonary

\section{Address for correspondence: Jinwoo Lee, M.D. \\ Division of Pulmonary and Critical Care Medicine, Department of Internal Medicine, Seoul National University Hospital, 101 Daehak-ro, Jongno-gu, Seoul 03080, Republic of Korea \\ Phone: 82-2-2072-7593, Fax: 82-2-762-9662 \\ E-mail: realrain7@gmail.com \\ Received: Nov. 27, 2020 \\ Revised: Nov. 29, 2020 \\ Accepted: Dec. 1, 2020 \\ Published online: Dec. 1, 2020 \\ (c) It is identical to the Creative Commons Attribution Non-Commercial License (http://creativecommons.org/licenses/by-nc/4.0/).}

disease such as acute pulmonary edema, acute respiratory distress syndrome (ARDS), and pneumonia ${ }^{1,5}$.

\section{Quantification of LUS Findings}

A controlled human model undergoing whole lung lavage showed that different states of lung aeration can be reliably detected by changes in LUS findings ${ }^{6}$. A progressive loss of aeration results in the switch from A-lines to B-pattern. A more severe loss of aeration responds as increasing number of Blines that coalesce and a complete loss of aeration is shown as a tissue-like pattern in LUS $^{7}$. The most frequently used approach is the LUS score, which is a semi-quantitative scoring system of four steps of progressive loss of lung aeration (Table 1). LUS score is calculated as the addition of scores in designated regions. The most popular method is dividing the lungs into 12 standard areas. Each hemithorax is divided into six areas by identifying anterior and posterior axillary lines and dividing each hemithorax in to upper and lower region. LUS scores can range from 0 (all areas well aerated) to 36 (all areas are consolidated $)^{5,8}$.

\section{Acute Pulmonary Edema}

Cardiogenic pulmonary edema is characterized by the homogenous distribution of multiple B-lines in all areas. LUS have been proven to be effective in the quantification of extravascular lung water and is comparable to more invasive methods $^{9-11}$. LUS has also shown that diuretic therapy or continu- 
Table 1. Lung ultrasound scores

\begin{tabular}{|cl|}
\hline Score & Characteristics \\
\hline 0 & Normal aeration or maximum of two isolated B-lines \\
1 & $\begin{array}{c}\text { Moderate loss of aeration with three or more } \\
\text { well-defined B-lines }\end{array}$ \\
\hline 2 & Severe loss of aeration with coalescent B-lines \\
\hline 3 & Complete loss of aeration with a tissue-like pattern \\
\hline
\end{tabular}

ous positive airway pressure in acute cardiogenic pulmonary edema is followed by decrease in the number of B-lines, suggesting that dynamic changes in the extravascular lung water can be monitored using LUS ${ }^{12,13}$. Tailored LUS-guided diuretic treatment of pulmonary congestion has also been associated with improved outcomes of patients with heart failure ${ }^{14}$. It is interesting to note that although natriuretic peptides are more frequently used for diagnosis and prognostication of acute cardiogenic pulmonary edema, their value as a guide for treatment has not yet been demonstrated ${ }^{15}$.

\section{Acute Respiratory Distress Syndrome}

Although the differential diagnosis of ARDS and cardiogenic pulmonary edema using LUS remains challenging, certain findings such as pleural line abnormalities, spared areas, consolidations may be used to distinguish the two diseases ${ }^{16}$. The regional LUS score of patients with ARDS correlated well with tissue density assessed with quantitative computed tomography ${ }^{17}$.

LUS can be used in different clinical context of patients with ARDS. The application of extracorporeal membrane oxygenation (ECMO) to patients with severe ARDS is increasing and its extended use in patients with less severe hypoxemia may be associated with favorable outcomes ${ }^{18}$. LUS may be used to monitor ARDS patients on $\mathrm{ECMO}^{19,20}$ in which bedside chest X-ray reveals only minimal information. It may also be used to assess aeration changes in ARDS patients, but there are contradictory results on its use in assessing positive endexpiratory pressure (PEEP) induced lung recruitment ${ }^{17,21}$. Moreover, improved aeration shown by LUS may not have a linear correlation with the improvement in oxygenation after prone positioning of ARDS patients ${ }^{22,23}$. Another limitation of LUS in patients with ARDS is that LUS cannot detect PEEPinduced lung hyperinflation.

\section{Pneumonia}

Ventilator-associated pneumonia (VAP) is one of the common complications of mechanical ventilation and is associated with prolonged ICU duration and increased medical
Table 2. Ventilator-associated pneumonia lung ultrasound score (VPLUS)

\begin{tabular}{|cl|}
\hline VPLUS & Parameter \\
\hline 1 & Purulent secretions \\
1 & $\geq 2$ areas with subpleural consolidations \\
2 & $\geq 1$ area with dynamic linear air-bronchogram \\
2 & $\begin{array}{c}\text { Positive direct gram-stain result or culture results of } \\
\text { endotracheal aspirate }\end{array}$ \\
\hline
\end{tabular}

costs. With the development of VAP, the normal LUS pattern is gradually substituted with focal areas of interstitial syndrome. With the aggravation of VAP, spaced B-lines increase in number and turn into coalescent B-lines and are often associated with subpleural consolidations ${ }^{24}$. Consolidations with a dynamic air-bronchogram (Supplementary Video S1) or subpleural consolidations in LUS may be useful for the diagnosis of $\mathrm{VAP}^{25}$. However, the diagnosis of VAP is challenging because LUS of patients under mechanical ventilation often presents severe loss of aeration from various etiologies not associated with infection ${ }^{26}$. VAP lung ultrasound score (Table 2) of more than 2 points identified VAP with $71 \%$ sensitivity and $69 \%$ specificity and its area under curve was higher than the Clinical Pulmonary Infection Score $(0.743 \text { vs. } 0.574)^{25}$. A single center randomized controlled trial showed that daily LUS screening for VAP in patients with purulent sputum was associated with longer ventilator free days compared to the control group using a combination of chest X-ray and clinical findings ${ }^{27}$. Also, VAP was diagnosed earlier and was less severe at the time of diagnosis in the LUS screening group.

\section{Weaning from Mechanical Ventilation}

The risk of complications associated with mechanical ventilation, increases with the duration of ventilator support. Patients requiring prolonged mechanical ventilation is at risk for increased medical cost and morbidity ${ }^{28}$. Given the risks associated with delayed or unsuccessful extubation, new methods are needed to assist with the weaning process. Changing from positive pressure ventilation to spontaneous breathing is often associated with significant lung derecruitment. In patients who successfully passed spontaneous breathing trial (SBT), changes in LUS scores are predictive of extubation success or failure ${ }^{29}$. In this study by Soummer et al. ${ }^{29}$, LUS was more accurate than B-type natriuretic peptide in identifying patients at higher risk for postextubation distress. LUS before and after SBT was also useful in diagnosing weaning-induced pulmonary edema ${ }^{30}$. However, another study showed that LUS before SBT failed to predict SBT failure ${ }^{31}$ which highlights the fact that not one method should be used in isolation to make decisions regarding critically ill patients. Although out of 
scope of this review, ultrasound of the heart, diaphragm and pleura may also be useful in detecting obstacles to successful extubation $^{32,33}$.

\section{Monitoring Response to Treatment}

LUS can be used to monitor aeration changes derived from treatment or procedure. The utilization of high-flow nasal cannula (HFNC) has continued to increase in various diseases and clinical situations ${ }^{34-36}$. Although strict monitoring of patients on HFNC is recommended to avoid delays in intubation and worse clinical outcomes ${ }^{37}$, monitoring methods and definitive signs to diagnose HFNC failure needs further research. LUS scores promise in this respect as it reflects positive changes in patients treated with HFNC oxygen therapy for blunt chest trauma ${ }^{38}$ and postextubation atelectasis in children $^{39}$.

\section{Limitations}

LUS evaluation has several limitations. LUS is operatordependent and requires training for acquisition of adequate images and correct interpretation. LUS cannot distinguish normal aeration from hyperinflation. It is difficult to assess patients with subcutaneous emphysema, subcutaneous edema, and large thoracic dressings or drains. Also, central lung lesions surrounded by normal lung parenchyma cannot be detected using LUS.

The traditional method of semiquantifying lung aeration also has limitations. The method of visualizing the pleura between the ribs helps identify the pleura but the view is limited by the width of the intercostal space which varies greatly among patients. Focal subpleural consolidations frequently seen in ARDS might lead to overestimation of aeration loss. To overcome these limitations, modified LUS score has been suggested $^{40}$ but needs further validation.

\section{Conclusion}

LUS is a simple, valuable bedside technique with numerous potentials as a monitoring tool. It can be used to monitor lung aeration changes in acute pulmonary edema, pneumonia, ARDS. It can also be used during mechanical ventilation and treatment for respiratory failure to monitor changes and response.

\section{Conflicts of Interest}

No potential conflict of interest relevant to this article was reported.

\section{Funding}

No funding to declare.

\section{Supplementary Material}

Supplementary material can be found in the journal homepage (http://www.e-trd.org)

Supplementary Video S1. Video of dynamic air-bronchogram.

\section{References}

1. Volpicelli G, Elbarbary M, Blaivas M, Lichtenstein DA, Mathis G, Kirkpatrick AW, et al. International evidence-based recommendations for point-of-care lung ultrasound. Intensive Care Med 2012;38:577-91.

2. Singh Y, Tissot C, Fraga MV, Yousef N, Cortes RG, Lopez J, et al. International evidence-based guidelines on Point of Care Ultrasound (POCUS) for critically ill neonates and children issued by the POCUS Working Group of the European Society of Paediatric and Neonatal Intensive Care (ESPNIC). Crit Care 2020;24:65.

3. Xirouchaki N, Magkanas E, Vaporidi K, Kondili E, Plataki M, Patrianakos A, et al. Lung ultrasound in critically ill patients: comparison with bedside chest radiography. Intensive Care Med 2011;37:1488-93.

4. Winkler MH, Touw HR, van de Ven PM, Twisk J, Tuinman PR. Diagnostic accuracy of chest radiograph, and when concomitantly studied lung ultrasound, in critically ill patients with respiratory symptoms: a systematic review and meta-analysis. Crit Care Med 2018;46:e707-14.

5. Mongodi S, Santangelo E, De Luca D, Rovida S, Corradi F, Volpicelli G, et al. Quantitative lung ultrasound: time for a consensus? Chest 2020;158:469-70.

6. Via G, Lichtenstein D, Mojoli F, Rodi G, Neri L, Storti E, et al. Whole lung lavage: a unique model for ultrasound assessment of lung aeration changes. Intensive Care Med 2010;36:999-1007.

7. Mojoli F, Bouhemad B, Mongodi S, Lichtenstein D. Lung ultrasound for critically ill patients. Am J Respir Crit Care Med 2019;199:701-14.

8. Via G, Storti E, Gulati G, Neri L, Mojoli F, Braschi A. Lung ultrasound in the ICU: from diagnostic instrument to respiratory monitoring tool. Minerva Anestesiol 2012;78:1282-96.

9. Agricola E, Bove T, Oppizzi M, Marino G, Zangrillo A, Margonato A, et al. "Ultrasound comet-tail images": a marker of pulmonary edema: a comparative study with wedge pressure 
and extravascular lung water. Chest 2005;127:1690-5.

10. Anile A, Russo J, Castiglione G, Volpicelli G. A simplified lung ultrasound approach to detect increased extravascular lung water in critically ill patients. Crit Ultrasound J 2017;9:13.

11. Mayr U, Lukas M, Habenicht L, Wiessner J, Heilmaier M, Ulrich J, et al. B-lines scores derived from lung ultrasound provide accurate prediction of extravascular lung water index: an observational study in critically ill patients. J Intensive Care Med 2020 Nov 5 [Epub]. https://doi.org/10.1177/088506662 0967655.

12. Ohman J, Harjola VP, Karjalainen P, Lassus J. Focused echocardiography and lung ultrasound protocol for guiding treatment in acute heart failure. ESC Heart Fail 2018;5:120-8.

13. Strnad M, Prosen G, Borovnik Lesjak V. Bedside lung ultrasound for monitoring the effectiveness of prehospital treatment with continuous positive airway pressure in acute decompensated heart failure. Eur J Emerg Med 2016;23:50-5.

14. Rivas-Lasarte M, Alvarez-Garcia J, Fernandez-Martinez J, Maestro A, Lopez-Lopez L, Sole-Gonzalez E, et al. Lung ultrasound-guided treatment in ambulatory patients with heart failure: a randomized controlled clinical trial (LUS-HF study). Eur J Heart Fail 2019;21:1605-13.

15. Felker GM, Anstrom KJ, Adams KF, Ezekowitz JA, Fiuzat M, Houston-Miller N, et al. Effect of natriuretic peptide-guided therapy on hospitalization or cardiovascular mortality in high-risk patients with heart failure and reduced ejection fraction: a randomized clinical trial. JAMA 2017;318:713-20.

16. Copetti R, Soldati G, Copetti P. Chest sonography: a useful tool to differentiate acute cardiogenic pulmonary edema from acute respiratory distress syndrome. Cardiovasc Ultrasound 2008;6:16.

17. Chiumello D, Mongodi S, Algieri I, Vergani GL, Orlando A, Via G, et al. Assessment of lung aeration and recruitment by CT scan and ultrasound in acute respiratory distress syndrome patients. Crit Care Med 2018;46:1761-8.

18. Kim WY, Park S, Kim HJ, Baek MS, Chung CR, Park SH, et al. Extended use of extracorporeal membrane oxygenation for acute respiratory distress syndrome: a retrospective multicenter study. Tuberc Respir Dis 2019;82:251-60.

19. Mongodi S, Pozzi M, Orlando A, Bouhemad B, Stella A, Tavazzi G, et al. Lung ultrasound for daily monitoring of ARDS patients on extracorporeal membrane oxygenation: preliminary experience. Intensive Care Med 2018;44:123-4.

20. Lu X, Arbelot C, Schreiber A, Langeron O, Monsel A, Lu Q. Ultrasound assessment of lung aeration in subjects supported by venovenous extracorporeal membrane oxygenation. Respir Care 2019;64:1478-87.

21. Bouhemad B, Brisson H, Le-Guen M, Arbelot C, Lu Q, Rouby JJ. Bedside ultrasound assessment of positive end-expiratory pressure-induced lung recruitment. Am J Respir Crit Care Med 2011;183:341-7.

22. Haddam M, Zieleskiewicz L, Perbet S, Baldovini A, Guervilly C, Arbelot C, et al. Lung ultrasonography for assessment of oxygenation response to prone position ventilation in ARDS. Intensive Care Med 2016;42:1546-56.

23. Wang XT, Ding X, Zhang HM, Chen H, Su LX, Liu DW, et al. Lung ultrasound can be used to predict the potential of prone positioning and assess prognosis in patients with acute respiratory distress syndrome. Crit Care 2016;20:385.

24. Bouhemad B, Liu ZH, Arbelot C, Zhang M, Ferarri F, Le-Guen $\mathrm{M}$, et al. Ultrasound assessment of antibiotic-induced pulmonary reaeration in ventilator-associated pneumonia. Crit Care Med 2010;38:84-92.

25. Mongodi S, Via G, Girard M, Rouquette I, Misset B, Braschi A, et al. Lung ultrasound for early diagnosis of ventilator-associated pneumonia. Chest 2016;149:969-80.

26. Bouhemad B, Dransart-Raye O, Mojoli F, Mongodi S. Lung ultrasound for diagnosis and monitoring of ventilator-associated pneumonia. Ann Transl Med 2018;6:418.

27. Pradhan S, Shrestha PS, Shrestha GS, Marhatta MN. Clinical impact of lung ultrasound monitoring for diagnosis of ventilator associated pneumonia: a diagnostic randomized controlled trial. J Crit Care 2020;58:65-71.

28. Roh J, Shin MJ, Jeong ES, Lee K. Association between medical costs and the ProVent model in patients requiring prolonged mechanical ventilation. Tuberc Respir Dis 2019;82:166-72.

29. Soummer A, Perbet S, Brisson H, Arbelot C, Constantin JM, Lu Q, et al. Ultrasound assessment of lung aeration loss during a successful weaning trial predicts postextubation distress. Crit Care Med 2012;40:2064-72.

30. Ferre A, Guillot M, Lichtenstein D, Meziere G, Richard C, Teboul JL, et al. Lung ultrasound allows the diagnosis of weaning-induced pulmonary oedema. Intensive Care Med 2019;45:601-8.

31. Antonio ACP, Knorst MM, Teixeira C. Lung ultrasound prior to spontaneous breathing trial is not helpful in the decision to wean. Respir Care 2018;63:873-8.

32. Mayo P, Volpicelli G, Lerolle N, Schreiber A, Doelken P, Vieillard-Baron A. Ultrasonography evaluation during the weaning process: the heart, the diaphragm, the pleura and the lung. Intensive Care Med 2016;42:1107-17.

33. Elshazly MI, Kamel KM, Elkorashy RI, Ismail MS, Ismail JH, Assal HH. Role of bedside ultrasonography in assessment of diaphragm function as a predictor of success of weaning in mechanically ventilated patients. Tuberc Respir Dis 2020;83:295-302.

34. Chung SM, Choi JW, Lee YS, Choi JH, Oh JY, Min KH, et al. Clinical effectiveness of high-flow nasal cannula in hypoxaemic patients during bronchoscopic procedures. Tuberc Respir Dis 2019;82:81-5.

35. Kim EJ, Jung CY, Kim KC. Effectiveness and safety of highflow nasal cannula oxygen delivery during bronchoalveolar lavage in acute respiratory failure patients. Tuberc Respir Dis 2018;81:319-29.

36. Lee JH, Rehder KJ, Williford L, Cheifetz IM, Turner DA. Use of high flow nasal cannula in critically ill infants, children, and 
adults: a critical review of the literature. Intensive Care Med 2013;39:247-57.

37. Kang BJ, Koh Y, Lim CM, Huh JW, Baek S, Han M, et al. Failure of high-flow nasal cannula therapy may delay intubation and increase mortality. Intensive Care Med 2015;41:623-32.

38. Lu X, Wu C, Gao Y, Zhang M. Bedside ultrasound assessment of lung reaeration in patients with blunt thoracic injury receiving high-flow nasal cannula oxygen therapy: a retrospective study. J Intensive Care Med 2020;35:1095-103.
39. Lee JH, Ji SH, Jang YE, Kim EH, Kim JT, Kim HS. Application of a high-flow nasal cannula for prevention of postextubation atelectasis in children undergoing surgery: a randomized controlled trial. Anesth Analg 2020 Nov 20 [Epub]. https:// doi.org/10.1213/ANE.0000000000005285.

40. Mongodi S, Bouhemad B, Orlando A, Stella A, Tavazzi G, Via G, et al. Modified lung ultrasound score for assessing and monitoring pulmonary aeration. Ultraschall Med 2017;38:530-7. 